\title{
artículos
}

\section{La Flor del Carmelo. Iconografía y mensaje simbólico de la iglesia conventual del Carmen de Antequera (II)}

\author{
María José Carmona Mato \\ Investigadora vinculada a la UMA
}

\section{RESUMEN}

Continúa el estudio iconográfico de la Iglesia del Carmen de Antequera, uno de los más sobresalientes exponentes de la arquitectura y artes plásticas del Barroco en Andalucía. PALABRAS CLAVE: Iconografía y sombología del "Carmen”/ Arquitectura/ Órdenes Religiosas/Barroco/Iglesia/Antequera/ Andalucía.

The flower of the Carmelo. Iconography and symbolic message of the conventual church of Carmen of Antequera (II)

ABSTRACT

This article is the second part of our study about the Church of Our Holy Mother of "El Carmen" in Antequera (town located in the province of Málaga, Spain) and its iconographical cycle. This temple is considered one of the greatest examples of the Baroque Art in Andalusia.

KEY WORDS: Iconography and Symbolical Meaning of "Carmen" / Architecture/ Religious Orders/ Baroque/ Church/ Antequera/ Andalusia.

\section{El Retablo de San Elías.}

La base arquitectónica del retablo del lado del Evangelio, que continúa directamente la línea eliana, se estructura en altura en tres niveles. Sobre el banco del retablo, el primer y segundo cuerpo se divide en tres calles o ejes, separadas en el primer caso por volutas y en el segundo por recargados estípites. Pero lo que resulta verdaderamente sorprendente y original es el tercer cuerpo o ático del mismo. En él, una enorme hornacina con dosel acoge a figuras que representan la conocida escena bíblica de II Reyes 2-13, Elías arrebatado a los cielos en un carro de fuego. Este tema -que alcanzó gran difusión ya que se asemejaba la ascensión de Elías a los cielos con la de Cristo-, contaba además iconográficamente con un precedente en el arte clásico: la figura de Helios-Apolo sobre su carro de fuego. Ésta será tomada por la forma tradicional de representar dicho episodio, si bien el mismo tuvo sus variantes según aparece en obras medievales en las que el profeta aparece en un carro sin caballos; o bien, llevado por caballos pero sin carroza. Nuestra escena es

* CARMONA MATO, María José: "La Flor del Carmelo. iconografía y mensaje simbólico de la iglesia conventual del Carmen de Antequera (II)", en Boletín de Arte, $\mathrm{n}^{\circ}$ 30-31, Departamento de Historia del Arte, Universidad de Málaga, 2009-2010, págs. 185-201. Fecha de recepción: Enero 2009. 


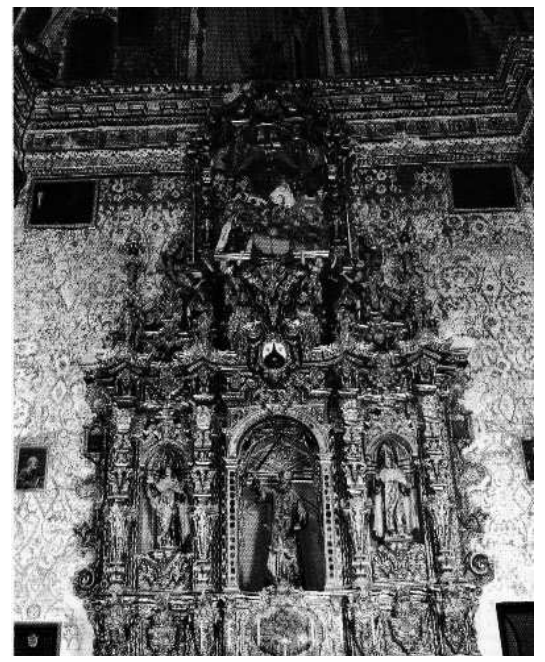

1. Retablo de San Elías. Iglesia del Carmen (Antequera).

más fiel a la iconografía tradicional y nos presenta a Elías que, vestido con el hábito carmelitano, se eleva al cielo sobre un carro tirado por dos caballos; mientras levanta su mano derecha hacia Dios, con la izquierda lanza su capa a Eliseo. Éste, también vestido con el hábito de la Orden, se encuentra arrodillado en el suelo cegado por la visión. Se le representa calvo siguiendo la narración de // Reyes 2, 18-24 en la que se cuenta que un grupo de pilluelos se rieron de su calvicie. El simbolismo del rapto nos remite a pensar en la especial asistencia de Dios para con el justo en el momento de la muerte. Esto es lo que nos quiere expresar esta escena, pues, según Eliseo, que fue el único que lo presenció, como nos indica I Macabeos 2, 58, Elías desapareció en un torbellino, es decir, fue arrebatado de la tierra directamente por Dios. La ascensión de Elías a los cielos se toma como imagen de la de Cristo y, de esta manera, el prestigio y santidad del fundador del Carmelo aumenta. Por citar algunas obras antiguas de las muchas existentes sobre este motivo, podemos recordar el fresco del cementerio de Domitila en Roma, los sarcófagos paleocristianos del Louvre y de la Basílica Vaticana, los relieves de las puertas de madera de Santa Sabina en Roma, miniaturas medievales o los relieves de la Catedral de Cremona del siglo XII, entre otros ${ }^{1}$.

La insistencia en este tema por parte de los Carmelitas para representar a su fundador es evidente. Se trata del momento en que Elías deja como sucesor suyo a Eliseo. Es más, Dios elige directamente a Eliseo (I Reyes 19,16$)$ para que vaya en

${ }^{1}$ NEGRI ARNOLDI, Francesco. “Elías.”, Iconografía, en SAGGI, L (Coord).: Santos del Carmelo, Madrid, Ed. de Espiritualidad, 1982, págs. 210-212.. 
seguimiento de Elías (I Reyes 19, 19ss) del cual heredará su espíritu en la medida establecida por la Ley para los primogénitos: el doble que los otros herederos (II Reyes 2, 1-15)2. Eliseo es así el primer eslabón de una cadena de santos carmelitas que serán sucesores e imitadores de Elías, los cuales marcarán esa línea ininterrumpida desde el Antiguo Testamento que a la Orden tanto le interesa resaltar. Es más, San Gregorio y San Nilo ven el en rapto de Elías la recompensa a su pureza, que ha de entenderse como la pureza monástica, la "apátheia" 3

Del ático pasamos al cuerpo central, que en este caso no es el principal, pues el protagonismo lo tiene en este caso el ático; en tanto hace de intercesión un relieve del escudo carmelitano. En la hornacina central una imagen de vestir de San Elías mantiene su brazo derecho en alto con una espada rizada o llameante y con la mano izquierda al nivel de la cintura sostiene un libro abierto. Justo delante de ella una pequeñísima figura de Santa Teresa con idéntica postura también mantiene su mano izquierda en alto mientras en la derecha lleva otro libro abierto. En las hornacinas laterales a izquierda y derecha las tallas de dos santos con rostros jóvenes y muy expresivos. El primero de ellos es San Ángelo de Sicilia con una cimitarra clavada en la cabeza, pues, según la leyenda este santo sufrió este tipo de martirio. El segundo con mitra y báculo curvado podía ser San Pedro Tomás o San Andrés Corsino. En este último caso, no podemos tener certeza de su identidad sólo reconocer que fue obispo, arzobispo o patriarca. San Ángel de Sicilia, según una tradición narrada en las Acta Sanctorum (s. XIV-XV), que actualmente parece digna de crédito, llegó a la isla de Sicilia con otros religiosos que emigraron desde el Carmelo y murió en Licata a los 35 años asesinado por los "infieles" de esta manera. Por ello se le considera mártir. La figura de San Ángel fue muy criticada por los bolandistas. A mediados del siglo XVII los jesuitas .J. Bolland, A. Henschen y D. Papenbroeck publican sus Acta Sanctorum, fruto de su insistencia en aplicar un método crítico a las fuentes. En esta obra arremeten contra la historia carmelitana, contra sus orígenes elianos y contra los relatos de las vidas de sus santos. La vida de San Ángel será la piedra de toque en la discordia que enfrentará durante largo tiempo a jesuitas y carmelitas. Actualmente el mismo padre Saggi afirma: "la vida de San Ángel es un ejemplo de cómo de elementos ficticios e inconsistentes puede nacer una vida de un santo, contribuyendo a crear toda una corriente de devoción y de culto con expresiones artísticas muy valiosas". La iconografía de esta iglesia, muy posterior a esta controversia como sabemos, no parece preocuparse por dichas críticas. Es más, enfrenta a esta figura un relieve tallado en el púlpito del mismo santo pero representado con una espada clavada en el pecho; quizás se trate de una alusión a una historia legendaria atribuida a un tal Enoc y conocida ya en el siglo XIV. Este reato nos narra cómo San Ángelo trató de convertir al conde Berengario que estaba amancebado con su propia hermana. Ésta se convirtió y el conde se vengó subiendo al púl-

\footnotetext{
2 STRAMARE, T.: "Eliseo" en SAGGI, L. (Coord.): op. cit., pág. 289.

3 PETERS, C.: "Elías, profeta, santo" en SAGGI, L.(Coord): op. cit., pág. 203.
} 
pito y asestándole siete puñaladas mientras predicaba 4 . Si bien, en este caso el puñal se habría sustituido por una espada por error, o habría sido ésta añadida posteriormente ante la pérdida de dicho atributo. Nos atrevemos a apuntar esta sugerencia, ya que, la espada actual de metal muy débil y totalmente rizada en su aspecto formal parece sustituir al atributo original. El culto a San Ángel se difundió especialmente entre los Carmelitas y el pueblo, hasta tal punto que en el Capítulo General de 1498 se prescribió que todos los conventos carmelitanos lo conmemoraran diariamente.

En el primer cuerpo, sobre el banco del retablo, entre dos cornucopias que se sitúan en el centro de las calles laterales, advertimos en la calle central, bajo la figura de San Elías, un relieve de forma ovalada que representa el Carmelo. En él reconocemos el monte, la fuente, la cueva, el templo, etc. Así, se sitúa a Elías en esta tierra que da nombre a la Orden. Añadir que, a izquierda y a derecha del retablo a la altura del ático, se colocan dos cuadros, y al nivel del cuerpo central otros dos más pequeños. Los primeros, dada la gran altura a que están colocados y la suciedad de los mismos, son difíciles de identificar, si bien, el de la izquierda pudiera ser una Magdalena penitente. Los segundos sí están en muy buenas condiciones y reconocemos en el de la izquierda a San Pedro por las llaves, siendo el de la derecha San Pablo. Francesco Spadafora nos refiere cómo en una homilía de San Juan Crisóstomo al pueblo de Antioquía ${ }^{5}$ se afirma que ha de verse en la sucesión de Elías en Eliseo, al cual entrega su manto, una prefiguración de los poderes que Cristo transmite a sus apóstoles y particularmente de la entrega de las llaves a San Pedro. Una transmisión de poder por investidura, que se presenta en una miniatura de la Biblia de Souvigni (s.XII) conservada en el Museo de Moulins y en una pintura de Gaspard Duhet en la Iglesia de San Martin ai Monti en Roma. La colocación de este cuadro junto a la escena del rapto de Elías al parecer no es casual, sino que se hace con esta intención expresa. La imagen de San Pablo al otro lado puede significar la extensión de la sucesión de manera universal, como el Carmelo desde siempre ha pretendido.

\section{El Retablo del Cristo de las penas.}

Este retablo del lado de la Epístola es muy semejante al anterior tanto en su base arquitectónica como en su profusa ornamentación. Su estructura también se divide en altura, en tres niveles sobre el banco del retablo, y el primer y segundo cuerpo se estructura en tres ejes o calles, siendo la central mucho más ancha que las laterales. Dichas calles, al igual que en el retablo con el que hace pareja, se sitúan en el primer cuerpo entre protuberantes volutas y en el segundo entre grandes y recargados estípites. Sin embargo, la impresión que nos produce no es esa, debido

\footnotetext{
4 SAGGI, L: "Angel de Sicilia, santo" en SAGGI, L.(Coord.): op. cit., págs. 243-247

5 SPADAFORA, F.:"Eliseo, profeta, santo", en SAGGI, L. (Coord): op. cit., págs 294-295.
} 
a que aquí se le resta importancia al ático y se le confiere todo el protagonismo al cuerpo central, el cual va a contener el camarín del Cristo de las Penas, equivocadamente identificado en su iconografía por algunos autores como un Ecce Homo. Si bien, el conjunto de su estructura resulta más tradicional, la obstinación en el adorno, el apurado del detalle y la virtuosa factura del mismo lo definen como aún más plenamente tardobarroco.

En la parte superior o ático, que corona un ángel con una gran cruz, en una circunferencia enmarcada en una estructura sobresaliente y cuadrada, descubrimos la imagen de medio cuerpo en altorrelieve de una Virgen rodeada de trece ráfagas de rayos: la Virgen de la Soledad. Como suspendidos en el aire la custodian dos ángeles, al de la izquierda le falta el motivo pasionista y el de la derecha mantiene con sus manos una escalera. Entre los dos, en el centro, otro sostiene un cáliz

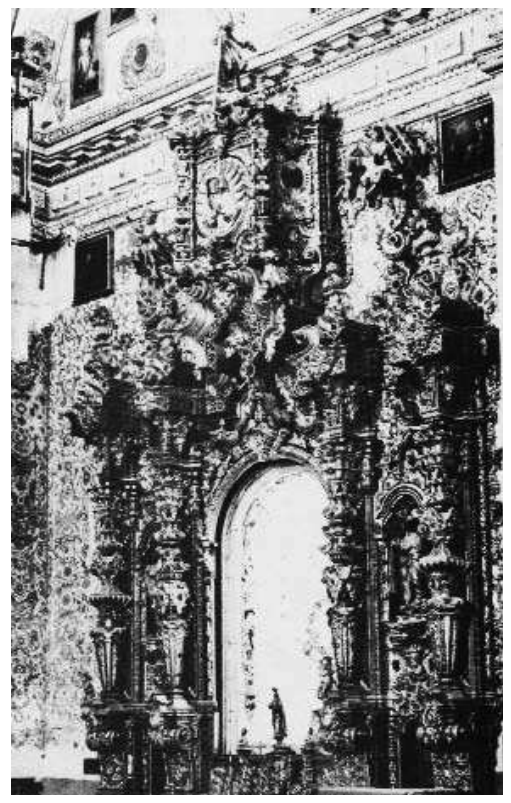

2. Perspectiva general del retablo del Cristo de las Penas. Iglesia del Carmen (Antequera). haciendo alusión conjunta a la Pasión de Cristo, de cuya síntesis teológica e iconográfica se hace eco la escultura del Cristo de las Penas -de rodillas, anhelante expresión y con las manos orantes entrelazadas-, claramente evocador del Cristo Mediador que, a la espera de la Crucifixión inminente, implora el perdón para sus enemigos mientras ofrece sus sufrimientos a Dios Padre por la Redención de la Humanidad6. A un nivel inferior, el cuerpo principal del retablo se divide en tres calles. La central considerablemente más ancha que las laterales, encierra el camarín que guarda la imagen del Cristo de las Penas, considerado como "la pieza más exquisita que produjo el barroco en Antequera"7. En las hornacinas de las calles laterales encontramos las esculturas de San Elesbán y Santa Ifigia, dos santos negros carmelitas príncipes etíopes. La postura de ambos es casi análoga, Santa Ifigia, a la izquierda, mantiene en mano izquierda a la altura del pecho un templo en llamas. San Elesbán, a la derecha, soporta sobre la misma mano y a la misma altura otro templo, mientras pisa con su pie izquierdo a un personaje del que sólo vemos la cabeza con corona de rey y las manos atadas. Por

6 SÁNCHEZ LÓPEZ, J.A.: El alma de la madera. Cinco siglos de icnografía y escultura procesional en Málaga, Málaga, Hermandad de la Amargura, 1996, p. 192.

7 ROMERO BENITEZ, J.: Guía artística de Antequera, Antequera, Ed. Biblioteca antequerana y Caja de Ahorros de Antequera, 1981, pág. 97. 
dichos atributos a ambos se les tiene como fundadores de conventos. Se colocan en el primer cuerpo sobre el banco del retablo, justo debajo de las hornacinas anteriores, entre enormes volutas, que contienen sendas pequeñas figuritas. La de la izquierda sujeta con la mano izquierda un ancla puesta hacia arriba y a sus pies tiene la inscripción "IN CELO" (hacia lo oculto). La de la derecha sostiene con el brazo derecho una columna y en la base escrito "SIETIT" (estuvo en pie). Ambas piezas hacen alusión al Cristo de las Penas, al igual que los cuatro pequeños angelitos con atributos de la Pasión que se sitúan entre ambas figuras como flotando en el aire, y haciendo de intersección entre las cuatro volutas del primer cuerpo y los cuatro grandes estípites que delimitan los ejes verticales del segundo. Portan de izquierda a derecha: una escalera, una barrena, un martillo y una cruz, y merecen resaltarse plásticamente, por el contraste de su tamaño con la estructura sobre la que se asientan y por su delicadeza y gracilidad.

En cuanto al camarín del Cristo de las Penas destaca realmente por su riqueza tanto arquitectónica como escultórica y pictórica, y por la exquisitez del conjunto. Su estructura se corresponde con la de los típicos camarines antequeranos de planta hexagonal que sigue la línea marcada por el que fue cabeza de serie, el de la Virgen de los Remedios (1709) ${ }^{8}$. Los paramentos cóncavos se continúan en los plementos igualmente cóncavos de la cúpula, la cual se forma con la superposición de dos anillos. En el primero se abren claraboyas cuatrilobuladas, quedando sustituida la central por un relieve del Padre Eterno. El segundo, mucho mayor que el primero, está totalmente decorado con pinturas. En cada uno de los elementos, y dentro de un marco simulado por la misma pintura, se representan de medio cuerpo a San Joaquín, San Elías, La Virgen del Carmen, San José, Santa Ana y San Juan Bautista. En el centro del camarín encontramos la interesante imagen arrodillada del Cristo de las Penas, como dijimos, con las manos atadas delante de la cintura, entronizada en un templete o "trono" de brazos convergentes. Dicho templete, junto con el de la Virgen de la Victoria de la Iglesia del mismo nombre de Málaga, serán los precedentes de este estilo, que, a su vez, darán lugar más adelante a los tronos actuales como elementos asociados a la función itinerante y procesional ${ }^{9}$. Sinuoso y dinámico, su estructura tiene tres cuerpos: una base maciza que hace las veces de peana, un espacio central abierto que deja que pase la luz e ilumine a la escultura en su totalidad, delimitado únicamente por los brazos que convergen en la parte superior, que, a su vez, sustentan la espléndida corona que culmina el conjunto. Por toda la estructura revolotean angelitos rubios que portan atributos de la Pasión. Delante del conjunto se sitúa una pequeña imagen de la Virgen.

Tradicionalmente las iglesias carmelitas suelen dedicar el retablo del lado de

8 ROMERO BENITEZ, J.: "Camarines antequeranos del siglo XVIII", en Jábega na. 13, 1976, págs 25-29.

$9 \mathrm{Mi}$ agradecimiento al Prof. Dr. Juan Antonio Sánchez López por esta aportación. Véase al respecto, SÁNCHEZ LÓPEZ, J.A.: "Del templo a la calle, del retablo al trono procesional”, SUR, 2-IV-2010. 

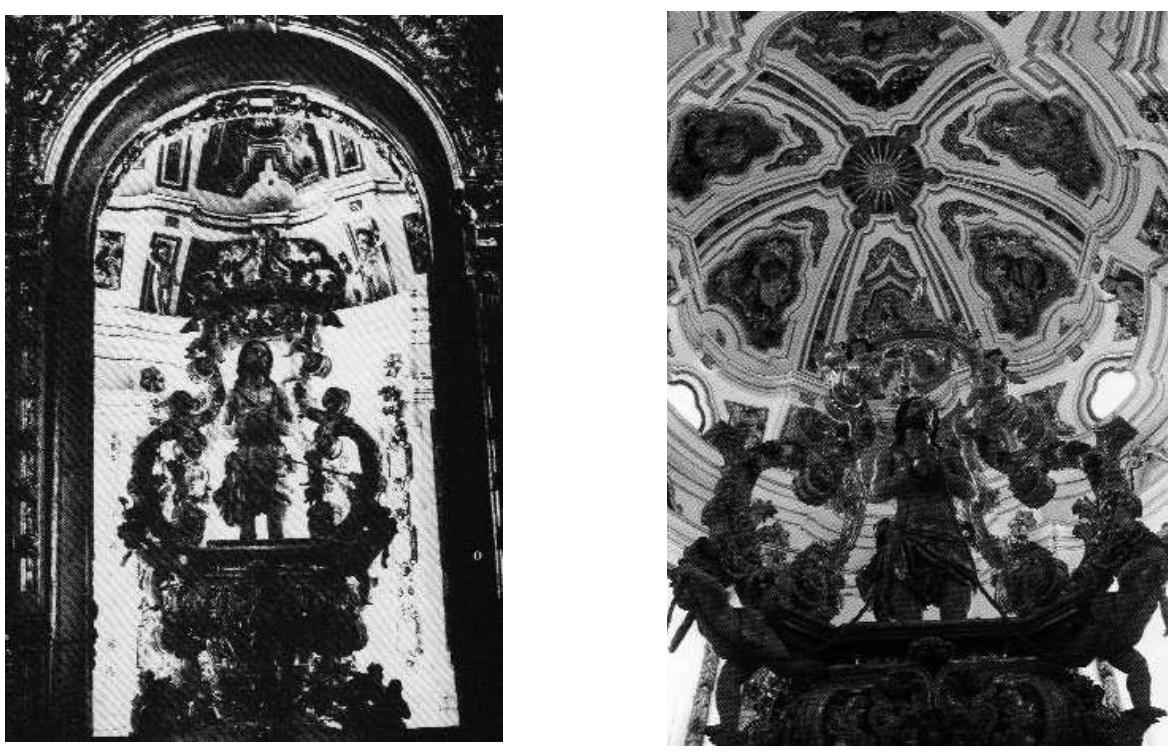

3. $\boldsymbol{y}$ 4. Embocadura, camarín y trono del Cristo de las Penas en el crucero de la Iglesia del Carmen (Antequera).

la Epístola a San José. Al respecto, esta iglesia parece bastante particular. Ni siquiera cabe la posibilidad de que se proyectase así en un principio y luego no se llevase a cabo y se colocara en su lugar al Cristo de las Penas, ya que, un camarín tan espectacular solamente puede estar dedicado a una figura de primera magnitud. Tanto las imágenes que se distribuyen por el retablo como la decoración del camarín, dadas su analogías con las del retablo central, pudieran ser obra de Diego Márquez y Vega 10 .

Ya fuera del retablo, a la misma altura que la Virgen de la Soledad se sitúan dos cuadros. Uno de ellos, el de la izquierda, guarda relación con el Cristo de las Penas, se trata de Cristo azotado por los sayones. El de la derecha es un retrato de Santa Teresa. Al mismo nivel que ocupaban los cuadros de San Pedro y San Pablo en el retablo del lado del Evangelio, aquí encontramos dos inscripciones: a la izquierda "ALTAR" y a la derecha "ANIMA“. El altar es el centro del culto sacrificial y el signo de la presencia divina. En el sacrificio perfecto el signo cede el puesto a la realidad: Cristo es a la vez sacerdote, víctima y altar. Es decir, es a la vez el lugar donde se va a producir el sacrificio y el lugar de la presencia divina. Es, por lo tanto, el altar vivo. Como es el que realiza la acción y a la vez es ofrecido por el Padre es sacerdote y víctima. Y se ofrece en sacrificio por las "Almas" de la humanidad. Por tanto,

10 ROMERO BENÍTEZ, J.: Guía artística de Antequera...op. cit., pág. 97. 
ambas inscripciones hacen alusión a la figura del Varón de Dolores, al tiempo que indican la condición privilegiada del conjunto como lugar propicio para el culto a las Ánimas del Purgatorio y la impetración de la redención de su pena por parte de los fieles que a él se acerquen.

Sobre ambos retablos colaterales, en sendos cuerpo semicirculares, se abren dos ventanas que permiten entradas de la luz a la capilla mayor. A cada lado, flanqueando las ventanas, se han colocado cuatro pinturas que al estar situadas a gran altura resulta difícil identificarlas y evaluarlas. Con todo, no parecen guardar relación temática alguna con el conjunto. Acertamos a identificar en las de la ventana de la izquierda, sobre el retablo de San Elías, arriba a San José con el Niño, abajo una Inmaculada con una bola del mundo a sus pies. A la derecha, arriba, una figura con el hábito carmelitano, un libro y azucenas, por tales atributos podría tratarse de San Alberto de Sicilia. Bajo él un San Francisco de Asís que resalta por su interés iconográfico dado su parecido con la escultura de Pedro de Mena que hay en el Museo de la ciudad de Antequera ${ }^{11}$. En el lateral derecho, sobre el retablo del Cristo de las Penas, tenemos arriba, a la izquierda, un obispo carmelita y abajo un San Sebastián. A la derecha en la parte superior un santo carmelita y bajo él un santo franciscano con una cruz en la mano izquierda y un niño en el cinturón (podría ser, desde luego, San Antonio de Padua). Destacar que en la parte más alta de éste lateral derecho, circundando la media esfera volvemos a encontrar los atributos de la Pasión de Cristo pintados en la pared, recordando de nuevo el tema central de este retablo, a saber: la lanza y la esponja, la corona, los tres clavos y las barrenas, las tenazas y el martillo y la parrilla y la cruz.

\section{El Coro.}

Frente a la cabecera de la iglesia, es decir, frente a la capilla mayor, encontramos a los pies de la misma, en las paredes del coro, una serie de cuatro grandes lienzos dedicados al parecer a uno de los "San Albertos". Sobre de cual San Alberto se trata hay dudas, pues, en los estudios de esta iglesia a veces aparece cono San Alberto de Sicilia o como el beato Alberto el Bienaventurado, nombre con el cual el autor parece referirse a San Alberto de Jerusalén ${ }^{12}$. Nosotros nos inclinamos más por el primero, pero evitamos el pronunciarnos con seguridad sobre ello. La incertidumbre es mayor por el hecho de que actualmente, dado el deterioro que estaban sufriendo, se encuentran depositados en el Museo Municipal de la ciudad. El hecho de que nos inclinemos por San Alberto de Sicilia se debe a que fue uno de los primeros santos carmelitas venerados en la Orden y más tarde considerado como

\footnotetext{
11 Ibídem, pág. 98.

12 PAREJO BARRANCO, A. y ROMERO BENÍTEZ, J. : "Restaurados en Sevilla dos grandes lienzos de la Iglesia del Carmen", El Sol de Antequera 5-IV-1981.
} 
"patrón" y "protector" de la misma. Ello explicaría haberse colocado esta serie en el coro del templo. Frente a la Patrona, la Virgen del Carmen, el Patrón, San Alberto de Sicilia.

Los temas de los lienzos son: el Nacimiento de San Alberto, la Toma del habito, el Tránsito y el Entierro. Jesús Romero nos dice que en el segundo de ellos el erudito José María Fernández quiso ver el retrato de Fray Ruiz de Barrionuevo, prior del convento. Como documento histórico pueden ser interesantes, porque aparecen ambientados en la época del artista. Incluso en el último de ellos aparece como fondo la propia Iglesia del Carmen y el Convento actualmen-

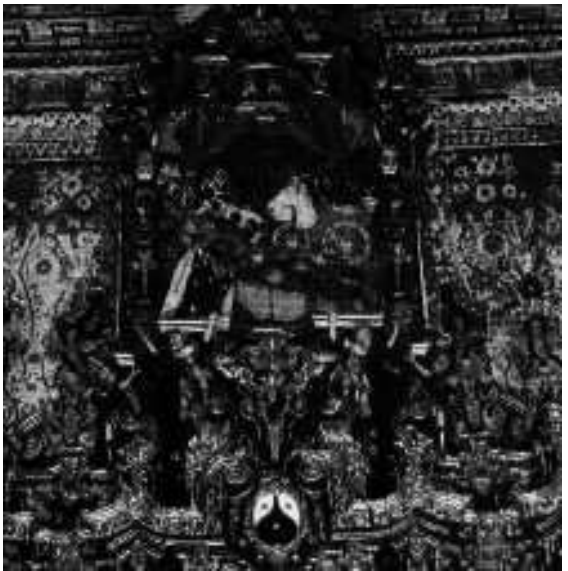

5. Ático del retablo de San Elías, con la representación del rapto del Profeta en un carro de fuego, en presencia de su discípulo Eliseo. te demolido, lo cual tampoco descarta

la posibilidad de que el cortejo fúnebre lo integren los mismos miembros de la comunidad conventual del momento. Según Romero, el dibujo y el colorido en general son débiles, quizás el de más calidad sea el del Tránsito. De hecho, los ángeles del rompimiento de gloria que aparece en el mismo recuerdan al gran lienzo de la Adoración de los pastores de Antonio Mohedano de la Iglesia parroquial de San Juan ${ }^{13}$.

La vida de San Alberto de Sicilia la conocemos por una "Vita" escrita en la segunda mitad del siglo XIV que nos ha llegado a través de numerosas copias y recopilaciones. Muchos de los elementos que aparecen en ella son tópicos de una tradición hagiográfica que, siguiendo datos bíblicos como los de Samuel, relata hechos como el de una madre estéril que, tras muchos años de matrimonio, concibe y le consagra el hijo a la Virgen. En el caso de Alberto, nace tras veintiséis años de matrimonio -otro caso conocido es el de San Andrés Corsino-. Entra en el Carmelo de Trápani y tras ser nombrado sacerdote y Superior Provincial de los Carmelitas de Sicilia, llega a ser un predicador muy célebre. Muere en Mesina en 1305 (en 1623 se le dedica una puerta de la ciudad). Se le atribuyen numerosos milagros incluso después que dejara este mundo. Se cuenta que, tras dicho momento, el pueblo y el clero discutían qué misa dedicarle, entonces dos ángeles bajaron del cielo y entonaron la antífona de la Misa de Confesores "Os justi". Con sus reliquias, distribuidas por toda Europa, se bendice el "Agua de San Alberto" empleada contra la fiebre aún actualmente. Calixto III lo canonizó en 1457, aunque hasta Sixto IV no se publicó la bula correspondiente. En 1420 el Capitulo había ordenado que

\footnotetext{
13 ROMERO BENITEZ, J.: op. cit., pág. 98.
} 
en todos los conventos se tuviera su imagen. En 1524 se ordenó que se representara su efigie en el sello del Capítulo General Superior de la Orden. Nicolás Audet ordenó que se le dedicara un altar en cada iglesia, lo cual explica su numerosa iconografía. En un principio, se le representó con o sin libro y con una azucena en la mano como símbolo de la victoria que en los comienzos de su vida religiosa obtuvo sobre sus sentidos. Más tarde, desde el siglo XVIII, se le representa realizando sus milagros. Normalmente, su atributo característico es un crucifijo entre dos ramos de azucenas, como se le representa en la escultura policromada de Alonso Cano en el convento de los Carmelitas de Sevilla (S. XVII), una de sus representaciones más famosas. La cabeza del santo se conserva en la Iglesia de los Carmelitas de su ciudad, Trápani. La celebración de San Alberto, es "fiesta" para los Carmelitas de la antigua observancia y "memoria obligatoria" para los Descalzos ${ }^{14}$.

Ya hemos visto cómo en los lugares principales de la iglesia se han situado las figuras más destacadas, pero también el resto del templo: la nave central e, incluso, el maravilloso púlpito van a contener obra pictórica y escultórica de otros santos carmelitas.

\section{EL PÚlPITO.}

El púlpito es una pieza especialmente destacable de la iglesia. Situado ante la capilla mayor, en el arco toral en el lado del Evangelio, como es norma en el Barroco. Esta fechado en su interior en el año 1799 y se realizó siendo prior fray Juan Romero. Su montera, respaldo y escalera son de madera y costaron 3650 reales, el dorado y estofado realizados por Miguel Jiménez y Juan Díaz supusieron un montante de 3.450 reales. Como escultor trabajó Miguel Márquez García. Su singular y elegante barroquismo encaja perfectamente con el conjunto de los retablos. Es el punto clave para dotar a la capilla mayor del particular gracejo que la caracteriza.

En la parte superior de la montera, culminando el conjunto, un niño coronado y con plumas en la cabeza sostiene con la mano izquierda un escapulario con el escudo del Carmen y con la derecha una bandera. En la parte interior de la misma, la paloma representativa del Espíritu Santo parece iluminar a cada uno de los santos que se sitúan en el púlpito. Pero antes de dar paso la caja del mismo, aún más cerca del Espíritu Santo, en el respaldo, encontramos una figura de Santa Teresa de Jesús, con birrete de doctora, que preside a las figuras que circundan la misma. En dicha caja se han esculpido en altorrelieve de medio cuerpo seis figuras que fácilmente identificamos, ya que aparecen con sus nombres correspondientes, son: San Cirilo doctor, San Pedro Thomás Mr Pcha (Patriarca), San Cirilo Pcha, San Ángelo, Santa Magdalena de Pazzi y Santa Ángela de Bohemia.

14 SAGGI, L. y RUOCCO, R.: "Alberto de Sicilia, o de Trápani, santo", en SAGGI, L.(coord.), op. cit., págs. 219-222. 
San Cirilo doctor tiene en sus manos unas tablas con la inscripción: DE PROCESSIONE SPIRITUS SANCTI. La leyenda hace referencia al episodio mas destacado de la vida de este personaje totalmente legendario, al que la tradición supone presbítero y ermitaño. Cuenta la historia que, en el transcurso de una misa, se le apareció un ángel y le entregó dos tablas de plata con inscripciones proféticas en caracteres griegos. Una vez las tradujo al latín, se las envió al abad Joaquín de Fiore ( $m$ 1202) del cual habría recibido una carta de respuesta. Juan de Rupescissa (1350) y Telesforo de Cosenza (1386) comentaron estas profecías, los "Oraculum angelicum", tan estimadas por los Espirituales. El carmelita F. Ribot (+ 1378) divulga una carta suya dirigida a Eusebio, prior de Monte Neroi, junto a Antioquía, y J. Grossi (hacia 1400) lo enumera entre los generales de la Orden. En el ámbito de la tradición joaquinita, los Franciscanos y Carmelitas, lo veneraron desde el s. XIII al XVI. Existen pocas representaciones suyas, dado que prácticamente es conocido sólo dentro de la Orden. Se le suele representar con el hábito carmelita, una corta barba blanca y a edad madura. Así aparece en esta representación y en el fresco de Gerardo de Starnino (s.XIV) en la Iglesia del Carmen de Florencia. En este caso en la inscripción se lee Pauper Cirilus presbiter eremita montis carmeli... in Domino eum obsercrandum. En la Iglesia de San Martin ai Monti, en Roma, existe un fresco de Jan Miel (s.XVII) en recuerdo de Cirilo apóstol de la Iglesia Oriental que lo representa bautizando a un sultán, siguiendo la leyenda que afirma que convirtió al de Iconio. Pero lo más curioso es que, en los siglos XV y XVI, muchos breviarios dicen que a él se debía haber conseguido la denominación para la Orden de "Hermanos de la Bienaventurada Virgen María" del Concilio de Éfeso. Se trata evidentemente de una confusión con su homónimo Cirilo de Alejandría, al que ya hemos hecho referencia ${ }^{15}$. Junto a él San Pedro Tomás con los atributos patriarcales como la mitra y el palio sobre el hábito carmelita y una lanza. Este santo nace en 1305 en el Périgod meridional (Le Breil). De origen muy humilde, vive los primeros años de su vida de la limosna. Entra en el convento de Berguerac, viste el hábito del Carmelo y es ordenado sacerdote. Dedica su vida al estudio y la enseñanza. Estudia Filosofía en Agén y enseña Lógica en numerosas ciudades. En 1345 fue elegido procurador general de la Orden y enviado a la Curia Papal de Avignón. Se gradúa en París como Maestro en Teología y es nombrado predicador apostólico. Tras esta distinción, su trayectoria cambia y desde 1353 lo tenemos dedicándose a los más altos cargos de la diplomacia pontificia. Colaboró en la pacificación entre los príncipes cristianos, en la defensa de los derechos de la Iglesia ante las monarquías de su tiempo, en la unión de los ortodoxos bizantinos eslavos con la Iglesia Romana, en la cruzada contra los musulmanes y en la liberación de Tierra Santa. Inocencio VI le nombra en 1354 obispo de Patti y Lupari y en 1359 lo eleva a la sede de Corón (Peloponeso) nombrándolo legado para oriente. En 1363 Urbano VIII lo promueve al arzobispado

15 STARING, A. (O. Carm) y CELLETTI, M. Ch.: "Cirilo de Constantinopla, santo" en SAGGI, L. (coord.), op. cit., págs. 271-273. 
de Creta y en 1364 es elegido patriarca latino de Constantinopla. Un año después, en 1365, muere de pulmonía en el convento carmelita de Famagusta de Chipre, dónde años antes, en 1358, tuvo varios éxtasis. Antes y después de su sepelio, se realizaron numerosos milagros. Inmediatamente después de su muerte, Mézieres y Carmerson escribieron su biografía para contribuir a su proceso de canonización. El culto al santo, confirmado por Pablo V en 1609 y por Urbano VIII en 1628, se celebra únicamente en la Orden del Carmen el día 3 de enero y en la diócesis de Périgod. La conquista de Chipre por los turcos y el terremoto borraron su memoria de la isla ${ }^{16}$.

A continuación, cuatro personajes que ya hemos tratado. San Cirilo de Alejandría con el hábito, la mitra y el palio patriarcal que lo acreditan como tal, sostiene en sus manos un libro en el que está escrito: "NON SED SOLUM THEOMATER TOCOS CHRISTI" ("NO SOLAMENTE MADRE DE CRISTO, SINO TAMBIÉN MADRE DE DIOS"). San Ángelo de Sicilia joven figura vestido de carmelita y con una espada clavada en el pecho. Santa Magdalena de Pazzi con ademán de sostener una cruz en sus brazos y Santa Ángela de Bohemia coronada y quizás un tarro (de perfume). A estas dos últimas figuras les falta el atributo.

Como lectura del conjunto, y una vez conocidas las diferentes biografías de cada uno de estos personajes, podríamos apuntar que es el Espíritu Santo, situado en la cima del púlpito, quien nos indica cómo Él es el que proporciona los diferentes carismas a cada uno de los personajes, el que los ilumina y les da la fuerza para llevar a cabo su misión. Cada uno de ellos en su ámbito, San Cirilo de Constantinopla como eremita y profeta, San Pedro Tomás como hábil diplomático, San Cirilo de Alejandría como defensor de la ortodoxia de la fe y Santa Magdalena de Pazzi con sus éxtasis reveladores de su doctrina, son frutos diferentes de un mismo árbol: el Carmelo ${ }^{17}$. Esta misma idea se refleja en un lienzo de la sacristía de esta iglesia en el que aparecen alrededor de una fuente muchos santos carmelitas: monjes, obispos, papas, etc, cogiendo con jarros el agua que brota de los diferentes caños de la misma. En la parte superior San Elías sostiene un templo, lo cual indica que, pese a las críticas, suspicacias y reticencias en sentido opuesto, él es el fundador de los Carmelitas. Pero los frutos aún se van a extender por toda la Iglesia y así, en la nave central, encontramos una serie de seis grandes lienzos con otros santos de la Orden.

\section{LA NAVE CENTRAL: LA SERIE DE LOS SANTOS.}

En los entrepaños de la parte inferior de la nave central se colocan seis grandes lienzos de santos carmelitas con sus correspondientes arbolitos simbólicos. Se sitúan en unas estructuras de madera que forman dos marcos exactamente iguales,

16 STIERNON, D.: “Pedro Tomás, santo” en SAGGI. L. (coord.), opus cit., págs. 427-439.

17 SAGGI, L..: "Hagiografía carmelitana" en SAGGI, L. (coord.): opus cit., pág. 134. 
pero de diferente tamaño uno sobre otro. Verdaderamente podrían definirse como dípticos. El gran marco que contiene el retrato del santo de cuerpo entero tiene a ambos lados sendas columnas corintias que sostienen un frontón partido, y detrás de cada lado de este frontón dos jarrones con flores también en madera. En el hueco del frontón encaja un marco exactamente igual para el correspondiente arbolito. En el hueco de este pequeño frontón, un sol con los rayos dorados y el centro de espejo, en el que se graban dibujos relativos a la Pasión, corona el conjunto. Bajo estas estructuras nos consta que hay otros lienzos del mismo estilo de los de la parte superior de esta misma nave; es decir, de los que ya hemos descrito de la serie mariana., pero en este caso dedicados a santos. Por ello, creemos que su realización se llevó a cabo en fecha posterior al resto de la iconografía de la iglesia.

Siguiendo el recorrido de las agujas del reloj encontramos en primer lugar a Santa Anoeta de rostro muy expresivo, vestida de monja y con una pluma en la mano derecha. Esta monja también debió de ser uno de esos personajes legendarios de la Orden cuyos datos biográficos tenían más de fantasía que de realidad, pues actualmente no aparece en aquellas hagiografías del Carmelo que pretenden ser estudios científicos. El arbolito que la acompaña es un ciprés. Este árbol es símbolo de la eternidad, dado el verdor perenne de sus hojas y del tránsito de la tierra al cielo por el su verticalidad. De ahí su empleo funerario ${ }^{18}$. Alciato en sus emblemas dice que acostumbró a cubrir la sepultura de los ilustres ${ }^{19}$. En nuestro caso puede tener ambos sentidos. Anoeta, por su santidad, tendría vida eterna, pasaría directamente de este mundo a los cielos, y sería reconocida como personaje ilustre de la Orden. Junto a ella, San Andrés Corsini ("Scorsín" según la inscripción) con atributos obispales, mira fijamente un crucifijo que sostiene en alto con la mano derecha. Este santo florentino se encontraba desempeñando el cargo de Superior de la provincia de Toscana (lo cual hizo durante dos años) cuando Clemente VI lo nombra en 1349 obispo de Fiésole. Famoso por sus virtudes y milagros era muy estricto en la administración, en la castidad y preparación del clero, en la concesión de beneficios eclesiásticos y con las donaciones destinadas a los enfermos y peregrinos, además de un árbitro insobornable en las disputas. Se preocupó mucho de los pobres, una disposición a favor de ellos en 1350 fue el primer acto documentado de su episcopado. También destaca de él su humildad y sobriedad, incluso vistió el hábito carmelitano durante toda su vida. En su sepultura se lee la inscripción: "Admirable por el ejemplo de su vida y por su elocuencia“. Sus virtudes fueron tan alabadas, que incluso después de su muerte, acaecida en 1374, el pueblo atribuyó a su intercesión la victoria en la batalla de Anghiari en el año 1440. Actualmente su cuerpo descansa en la Capilla Corsini de la Iglesia del Carmen de Florencia. Canonizado en 1629, su celebración litúrgica, el 9 de enero, es "fiesta" para los Carmelitas de la antigua observancia y "memoria libre" para los Descalzos ${ }^{20}$. En cuanto al árbol que se le atri-

18 REVILLA, F.: Diccionario de Iconografía, Madrid, Cátedra, 1990, pág. 91.

19 MORALES Y MARÍN, J. L.: Diccionario de Iconología y Simbología, Madrid, Taurus, 1984, págs 97-98. 
buye, advertimos que verdaderamente el simbolismo del granado se identifica bastante bien con la personalidad de San Andrés. Este árbol además de ser símbolo de la fertilidad, como el resto de los árboles, es símbolo de la abundancia al contener su fruto, la granada, multitud de granos bajo su corteza. Es curioso cómo la mística cristiana traspasa este simbolismo de fecundidad al plano espiritual. Para San Juan de la Cruz los granos de este fruto evocan las perfecciones de Dios21. En el caso que nos ocupa podrían evocar las perfecciones de nuestro santo, que fue tan venerado por las virtudes consideradas tradicionalmente por la Iglesia como las principales virtudes morales: Humildad, Penitencia, Modestia, Celo y Apostolado, Castidad y Continencia y Pobreza y Obediencia. En tercer lugar, la ya aludida Santa Magdalena de Pazzi, vestida de monja carmelita y portando una cruz de madera de tamaño superior al de su propia figura.

En el lado del Evangelio, continuando en el sentido de las agujas del reloj, nos encontramos con San Dionisio con la tiara y el bastón-cruz papal trirregno. Por tanto, se trata del Papa San Dionisio al que ya nos hemos referido. El arbolito que lo acompaña se parece mucho a una encina. Este árbol de madera muy dura, considerado uno de los más altivos y vistosos de la zona templada, es símbolo de la fortaleza, la solidez, la permanencia y la majestad. En la Biblia algunos hechos importantes están relacionados con él, como la revelación de Dios a Abraham en la encina de Mambré (Génesis 18). En el Renacimiento fueron recogidos estos significados y Rafael pinto en la Stanza de la Signatura la "Fuerza Moral" bajo una encina22. La simbología de este árbol concuerda perfectamente con la figura de San Dionisio, que arremetió con fuerza contra las numerosas herejías de su tiempo, proporcionando una gran solidez al cristianismo al defender la doctrina de la Trinidad en su permanente defensa de la ortodoxia de la fe, y aportando en ello la majestad que su dignidad eclesiástica le permitía.

Más adelante, Santa Febonia también figura vestida de monja carmelita y quizás degollada. Su arbolito identificativo constata su gran parecido con el anterior. Con todo, podría tratarse de un pino de copa muy ancha. El pino es identificado desde siempre con la inmortalidad, y su fruto, la piña, con la fertilidad 23 . Esta santa también debe considerarse actualmente como uno más de los personajes legendarios de la Orden, pues, tampoco tenemos datos sobre ella en los libros especializados más recientes. Sólo nos cabe sugerir que sus virtudes quedarían patentes en sus buenos frutos, es decir, en sus obras y ello la llevaría a conseguir la inmortalidad de su alma. Tal vez, tanto ella como Santa Anoeta son veneradas como mártires del Carmelo y por ello sus respectivos árboles simbólicos hacen referencia a la eternidad y a la inmortalidad. En sexto lugar tenemos al ya también citado San Cirilo de Alejandría con

\footnotetext{
20 SAGGI, L. y ORIENTI, S.: “Andrés Corsini, santo" en SAGGI, L. (coord.): op. cit., págs. 230-240.

21 REVILLA, F.: op. cit., pág. 172.

22 Ibídem, pág. 137.

23 MORALES Y MARÍN, J. L.: op. cit., pág. 272.
} 
atributos patriarcales como la mitra, el palio, la cruz pectoral y la cruz portante de dos brazos. Con la mano derecha coge la cruz pectoral y con la izquierda sostiene un libro. Su figura se asemeja bastante a la del retablo central. Su arbolito simbólico tiene cierto parecido con un olivo. El olivo de hoja perenne, es el árbol de Atenea y recuerda los valores más característicos de la misma: la sabiduría, la prudencia y la civilización. A ellos la tradición judeocristiana añade la simbología de la paz. Noé supo el término del diluvio porque una paloma le llevó una rama de olivo (Génesis 8, 11), lo que significaba que la cólera de Dios había cesado ${ }^{24}$. En Grecia se coronaba con una rama de olivo a los atletas vencedores ${ }^{25}$. El simbolismo de este árbol, por tanto, se puede aplicar a San Cirilo, el cual dada su sabiduría y prudencia supo salir victorioso en su enfrentamiento con Nestorio, proporcionando con ello la paz a la Iglesia.

Pero todo lo dicho aún puede llevarse más lejos. Si bien, antes de continuar, es necesario recordar que las relaciones entre árboles y personajes expuestas anteriormente son sólo hipótesis en clave de sugerencias que nos hemos atrevido a aportar basándonos sólo en lo que podemos contemplar. Para un estudio verdaderamente certero de dichas relaciones sería necesario contar con documentos de la época que nos informaran sobre las intenciones del mentor de dicho programa iconográfico. Siguiendo en la línea de las simples insinuaciones pensamos que el conjunto de los arbolitos simbólicos podría hacer referencia a las Virtudes Teologales y cardinales.

Si nos fijamos detenidamente, vemos que en el lado de la derecha tenemos dos santas y un santo en el centro, en el lado de la izquierda dos santos y una santa entre ellos. Por tanto, podemos formar dos triángulos, uno de personajes femeninos y otro de personajes masculinos. El primero, que tendría su base en el lado de la derecha, formarían las Virtudes Teologales: Fe, Esperanza y Caridad. Para ello, tendríamos que suponer que el árbol que falta, el correspondiente a la Santa de Pazzi, debería de simbolizar el Amor de Dios y al prójimo que tanto resalta en los escritos de Santa Magdalena. Entonces tendríamos en primer lugar la fe en la eternidad (ciprés), la esperanza en la inmortalidad (pino) y la caridad, el amor de Dios y al prójimo. El triángulo de las figuras masculinas con su base en el lado izquierdo contendría las Virtudes Cardinales: Fortaleza, Justicia, Prudencia y Templanza. Empezando por la fortaleza (encina) continuaría en la Justicia (granado) y llegaría a la prudencia y la templanza (olivo). Conviene aclarar que en la Biblia "justicia" significa "iustum facere", hacerse justo, es decir, contribuir al Plan de Dios. El hombre únicamente se hace justo y actúa con justicia cuando cultiva las virtudes morales como son la humildad, la modestia, la pobreza, etc. El granado hemos dicho que simbolizaría las virtudes morales del santo al que corresponde y, por ello, se le relacionaría con la justicia.

Por otra parte, y ya como aportación mucho más certera y contrastada, constatamos que los santos que encontramos en esta iglesia son todos ellos -excluyendo a los del retablo central que como hemos visto se veneran por otros motivos- san-

24 REVILLA, F.: op. cit., pág. 280.

25 MORALES Y MARÍN. J. L.: op. cit., pág. 245. 
tos protectores de la Orden. Entre 1462 y 1495 en un folio empleado por los Carmelitas para la lectura de su Martirologio, en el día 14 de junio, se enumeran nueve santos protectores de la Orden. Entre los seis primeros se citan a: Pedro Tomás, Andrés de Florencia (Corsino), Cirilo presbítero (de Constantinopla), Ángel (de Sicilia), Simón (Stock) y Eliseo ${ }^{26}$. Recordemos que Alberto de Sicilia también fue desde muy pronto considerado patrón y protector de la Orden.

\section{CONSIDERACIONES SIGNIFICACTIVAS A MODO DE CONCLUSIÓN.}

Sabemos que el retablo central y los dos laterales fueron realizados en los años anteriores a 1747 y el púlpito está fechado en 1799. Por lo tanto, el programa iconográfico de esta iglesia fue realizado muy posteriormente a lo que se llamó "La Gran Controversia", provocada por el jesuita Papenbroeck que se atrevió a decir que la tradición de la Orden en lo tocante a su antigüedad, y según documentos que aportaba, carecía de todo fundamento sólido. Propone comenzar la historia carmelitana en el siglo XII con Bertoldo y Brocardo a quién Alberto habría dado la regla. Criticaba el hecho de que los Carmelitas para tener a Elías como precursor llegaran a afirmar que había sido un monje con los tres votos religiosos y establecieran una serie continuada de ermitaños sucesores suyos. Para Papenbroeck lo que permitiría llamar a Elías y a Eliseo "fundadores" sería que sus sucesores hubiesen sido formadores y maestros de Brocardo y de sus compañeros.

EI Papa Inocencio XII (1691-1700) ante las presiones de los defensores de la tradición eliana y los partidarios de los bolandistas promulga la bula Redemptoris por la que, sin tomar partido por ninguna de las dos tesis, impone silencio. Pero su sucesor Clemente XI (1700-1724), según las actas del Capítulo General de la Orden celebrado en 1704 en Roma, en que se acuerda dar gracias al Papa, dará permiso para erigir en la Basílica Vaticana una estatua de Elías. Esto se llevará a cabo en 1725 con su sucesor Benedicto XIII (1724-1730) y, además, llevará la inscripción "La Orden carmelitana a su fundador el profeta Elías“. Más tarde, Benedicto XIV (17401758) defendía la obra de los bolandistas 27.

Si nos fijamos en las fechas que hemos indicado de realización de los retablos, de la imaginería que lo puebla y de la obra pictórica de la iglesia vemos que coinciden con los años del papado de Benedicto XIV y sus sucesores. De todas formas, hay que señalar que aunque este Papa aceptara la obra de los bolandistas, las vacilantes posturas de sus antecesores todavía debían de flotar en el ambiente. Con todo, pudiera sorprender una iglesia carmelitana tan apegada a la defensa de la tradición de la Orden como es la que estudiamos en una época tan controvertida. Por ello, se pueden dar al menos tres hipótesis sobre la formación de este programa tan abiertamente eliano:

26 SPADAFORA, F: "Eliseo....", pág 293.

27 SAGGI, L.: “Hagiografía carmelitana”.... págs. 93-112. 
1) que dicho programa continuara la línea de la "tradición eliana" de la Orden, que al parecer apoyaron Clemente VII y Benedicto XIII, porque la aceptación de las críticas a los orígenes del Carmelo hubiese sido simplemente un reconocimiento del Papa y careciera de una radicalidad tal como para afectar los proyectos de la Orden.

2) que los Carmelitas Calzados fueran abiertos defensores de la "tradición eliana" y decidieran apoyar un programa de este tipo, frente a la postura tomada por un Papa iluminista y abierto a los nuevos caminos de pensamiento como lo fue Benedicto XIV.

3) o bien, que los Carmelitas Calzados de la localidad antequerana permanecieran al margen de estas polémicas y siguieran fieles a las tradiciones del Carmelo.

Como se puede percibir, el estudio realizado sólo es una aproximación a lo que pudo ser el "programa iconográfico" de la Iglesia del Carmen de Antequera. Son necesarios análisis mucho más profundos basados en documentación de la época, de la Orden y de este convento antequerano concretamente, etc., para poder llegar a unas conclusiones verdaderamente ciertas de lo que significó la construcción de esta iglesia en su tiempo. Esperamos poder seguir completando y matizando este trabajo con posteriores investigaciones. 
